\title{
Introduction: Disordered Mood as Historical Problem
}

If mania and melancholia took on the face that we still recognise today, it is not because we have learnt to 'open our eyes' to their real nature during the course of the centuries; and it is not because we have purified our perceptive processes until they became transparent. It is because in the experience of madness, these concepts were integrated around specific qualitative themes that have lent them their own unity and given them a significant coherence, finally rendering them perceptible. ${ }^{1}$

Michel Foucault, History of Madness (1961)

In the summer of 1874, Moses B., a young doctor, was brought into Edinburgh Royal Asylum at Morningside. According to his family, he had become so intent on taking his own life that they saw no other option but to have him certified as insane and admitted to the hospital. One of the doctors who examined him in his home had written in the medical certificate that Moses suffered from severe 'delusions', which had him convinced that 'his soul is lost, that he ought to die' and that 'he is committing great sins'. When Moses arrived at Morningside, the attending physician noted in the patient journal that the young man's 'depression' was 'considerable', and made a note of his 'suicidal tendencies', which, based on family testimony, consisted in 'taking belladonna, refusing food, \&c'. Moses B. was subsequently diagnosed with melancholia, with emphasis given to his pronounced 'suicidal tendencies', which required that he be placed under close observation.

(C) The Author(s) 2021

Å Jansson, From Melancholia to Depression, Mental Health in Historical Perspective, https://doi.org/10.1007/978-3-030-54802-5_1 
For the experienced medical staff at Morningside, diagnosing Moses was a straightforward matter. Melancholia was, at the time, a common affliction among patients who arrived in the asylum. Its symptoms were considered to be clearly recognisable and, according to the institution's chief physician, Thomas Clouston, the disease ran 'a somewhat definite course, like a fever'. ${ }^{2}$ But what would a twenty-first-century psychiatrist or general practitioner make of a patient like Moses Black? Would they conclude that he suffered from Major Depressive Disorder, prescribe him a course of antidepressants, and put him on the waiting list for Cognitive Behavioural Therapy? Or would his thoughts and actions-believing himself to have sinned against God and attempting to poison himselfappear unfamiliar to today's clinicians? These questions speak to a more profound, ontological concern: is clinical depression a timeless condition? In other words, have people always been depressed?

I will return to this question momentarily. Whether or not depression has always been a feature of the human condition, if current statistics are to be believed we are, as a society, becoming more depressed with each passing year. According to the World Health Organisation, clinical depression is now the world's leading cause of disability. When a new generation of antidepressant drugs, selective serotonin reuptake inhibitors (SSRIs), flooded the market in the late twentieth century, one scholar suggested that we had entered an 'antidepressant era' ${ }^{3}$ In the 1990s, SSRIs became what benzodiazepines were to the sixties-the universal cure for unwanted negative emotions. A common question in response to these developments, which has been posed by scholars across the natural and human sciences, is whether rates of depression have increased, or whether we have become less tolerant of emotional distress, or simply more likely to denote it as a medical problem with a chemical solution. It has been suggested that the apparent rise in depression is primarily due to a growing tendency to over-diagnose 'normal sadness'. ${ }^{4}$ Others argue that there has been a real increase in the symptoms of genuine Major Depressive Disorder since the early twentieth century, leading one observer to conclude that depression is, like obesity and type-II diabetes, a 'disease of modernity' caused by humanity's collective derailment from our true evolutionary path, suggesting that 'humans have dragged a body with a long hominid history into an overfed, malnourished, sedentary, sunlight-deficient, sleep-deprived, competitive, inequitable, and sociallyisolating environment with dire consequences'. ${ }^{5}$ 
However, a different school of thought exists that has found support both in clinical circles and among some humanities scholars: that, historically, two types of depression have coexisted. ${ }^{6}$ One is a mild to moderate form of mood disorder, what is usually meant by the term 'clinical depression' today: low mood and sadness, often accompanied by sleeplessness, appetite disruption, and anxiety. The other is an endogenous form that is more than a mental disorder, it is an illness where the entire system is, in effect, 'pressed down', resulting in retarded speech and slow bodily movement. This illness often manifests with delusions (psychosis) and can in its most severe forms leave sufferers in a catatonic stupor. This condition is usually referred to as psychotic or melancholic depression. Existing research on this type of depression holds the promise of something that has eluded psychiatry since its infancy: a mood disorder with a traceable and measurable biological basis. Endocrine psychiatry indicates that individuals who fit the external symptomatology for melancholic depression show similar results when subjected to a Dexamethasone Suppression Test (DST) measuring the level of cortisol in the blood. Such research is, however, marginalised in the current neuro-focused climate where neurotransmitters are conceptualised as the cause, effect, and cure for depression, and where the major diagnostic manuals retain a descriptive focus. Another key feature of melancholic depression is its perceived resistance to standard antidepressant treatments such as SSRIs and behavioural therapies; instead, it is argued that patients tend to respond to a combination of electroconvulsive therapy and atypical (tricyclic) antidepressants. In recent years, a number of scholars and clinicians have sought to institute this type of depression into diagnostic literature as an illness in its own right: melancholia. ${ }^{7}$

This drive to formally institute melancholia into psychiatric diagnostic literature is presented as an attempted 'resurrection' of a condition that has existed throughout human history and been documented by physicians as far back as Hippocrates. This melancholia, its proponents argue, 'lends itself to definition as an independent entity in the classification' and 'is consistent with centuries of observation'. ${ }^{8}$ It is constituted as universal and timeless, the 'real' depression, whereas our time's standard clinical depression is seen to have more in common with the nervous disorders of the early modern period or neurasthenia in the nineteenth century. Authors beyond the psy disciplines who have adopted this view constitute a broad church, including historians, philosophers, and social scientists, 
and their work is prominent within existing scholarship on the history of melancholia. ${ }^{9}$

Max Fink and Michael Taylor, two psychiatrists who are at the forefront of the campaign to resurrect melancholia, argue that this disease is 'consistently' described in 'psychopathological literature' as 'a severe illness of acute onset with unremitting moods of apprehension and gloom, psychomotor disturbance, and vegetative signs. Psychosis, intermittent mania, and suicide intent are prominent features'. ${ }^{10}$ What is most noteworthy about this is not the definition itself, but that the 'psychopathological literature' referred to is from the mid-nineteenth century. Indeed, while those attempting to 'resurrect' melancholia assert that this illness has existed since the beginning of time, the disease they are seeking to revive appears to be an updated version of a diagnostic category specific to nineteenth-century psychological medicine.

What, then, is this nineteenth-century melancholia that some writers are attempting to bring back to life? Is it a timeless illness finally discovered and described by nineteenth-century doctors? It would certainly be possible to write the history of melancholic depression as the history of a medical condition that has existed since the dawn of humanity, and which was finally given an accurate scientific description in the nineteenth century. But this narrative ignores a number of important factors. First of all, the very idea of a 'mood disorder' was not possible before a modern, scientific model of emotion was created. Secondly, melancholic depression was not suddenly discovered with the help of modern medical science. Rather, the meaning of melancholia as a medical condition changedin other words, melancholia was reconceptualised as a modern mood disorder in the nineteenth century. This process required significant intellectual work, and was made possible by the appropriation of experimental physiology to talk about unseen and unmeasurable mental phenomena. The model of emotion that emerged in the early-to-mid-nineteenth century was not discovered, it was made-originally as an analogy of sensory-motor action, which eventually became a scientific concept in its own right. There was nothing inevitable about this development; as one scholar has suggested, implications had to be constructed rather than merely extrapolated'. ${ }^{11}$ Finally, as will be demonstrated in the chapters that follow, the melancholia that was described by nineteenth-century physicians and diagnosed in asylum patients had a distinct symptomatology, which does not seamlessly correspond to either the milder or the 'melancholic' depressions that are diagnosed today. 
There exists, then, a different history of melancholia and depression, one that is yet to be told. It is this history that is the focus of this book. It maps the first decades of melancholia as a biomedical disease, but rather than showing how this timeless illness was finally discovered and correctly described by modern psychiatry, this book tells the story of how the idea of a 'mood disorder' was created in the nineteenth century and subsequently made into a possible and plausible medical concept. This was a development that to some extent occurred simultaneously in several European countries; however, important national differences existed. For instance, French physicians were more concerned with melancholia as one stage of 'circular insanity' (the other being mania) than their German or British counterparts; indeed, British physicians held that cases of circular insanity were rare among their patients. Such geographical differences speak to the malleability of mental disorders not just across time, but also across cultural or linguistic contexts. This book is primarily concerned with melancholia in the British context, for three reasons. First of all, melancholia was consistently diagnosed in British asylums throughout the second half of the nineteenth century, and the wealth of asylum records and statistical reports, as well as prolific diagnostic literature on melancholia, offer an optimal space for interrogating this medical category. In many asylums across the country, melancholia was the second most common diagnosis after mania. From the mid-nineteenth century onward, the rate increased gradually, and at the same time, the diagnosis was gradually standardised. This coherence across asylums as far apart as Edinburgh and Sussex was in part the result of a standardised regime imposed by the Lunacy Commission from the 1840s onward, as well as growing professional interaction between asylum physicians through meetings and publications. Secondly, Germany is often presented in historical narratives as the cradle of modern psychiatric knowledge and the most important influence on contemporary diagnostics. This is in part due to the significance of Emil Kraepelin's work and the prominent place awarded to his nosology in both historical and contemporary texts on psychiatric diagnostics. However, while Kraepelin's division of mental disorders into dementia praecox and manic-depressive insanity at the turn of the twentieth century had a fundamental impact on the subsequent classification of insanity, his diagnostic system was the product and articulation of decades of accumulated knowledge, much of which originated within British psychological medicine. In particular, one of the most 
crucial developments of modern psychiatry and the focus of this bookthe creation of 'mood disorder' as a medical category-can in large part be attributed to the intellectual context of British asylum medicine. Finally, while a truly inter- or transcultural history of melancholia in this period would no doubt be a fascinating one, such an approach would limit the possibility for an in-depth study of its transformation. At the same time, however, the making of melancholia as a modern mood disorder in Victorian medicine did not occur in a national vacuum. The uptake of German and, to an extent, French medical knowledge into British psychological medicine was instrumental, and consequently forms part of the present story.

This book begins with early nineteenth-century experimental physiology and ends in the Victorian asylum at the turn of the twentieth century. Victorian physicians conceptualised melancholia as a form of affective insanity in which the intellect was left wholly or partially intact. During European psychiatry's foundational century biological disease models came to dominate, underpinned by increasingly refined medicoscientific technology, specifically microscopy. Physicians were able to 'see' into the brains of deceased patients in ways never before possible, and eagerly searched for cerebral lesions to support biomedical theories of mental disease. Contrary to one historian's suggestion that 'neuropsychiatry never really flourished in Britain', ${ }^{12}$ Victorian medical psychologists embraced neurological explanatory frameworks for mental disease. However, despite the spread and growing sophistication of psychiatric autopsies in Europe, some forms of madness consistently failed to turn up visible changes to brain tissue. ${ }^{13}$ This was particularly the case with milder forms of insanity where the emotions were seen as the chief site of pathology. In a biomedical context, such illness came to be explained primarily through functional physiological (rather than structural anatomical) language.

In 1883, Scottish asylum physician Thomas Clouston defined melancholia as 'mental pain, emotional depression, and sense of ill-being, usually more intense than in melancholy, with loss of self-control, or insane delusions, or uncontrollable impulses towards suicide, with no proper capacity left to follow ordinary avocations, with some of the ordinary interests of life destroyed, and generally with marked bodily symptoms'. ${ }^{14}$ At this time, melancholia was not only one of the most common forms of mental disease diagnosed in British asylums, it was also one of the most standardised and homogenous diagnoses, both in terms 
of a coherent symptom picture and an internal biological explanatory model. Yet only a few decades earlier, the nosological status of melancholia in British (and European) medicine was unclear and unstable, with some of the most prominent medical writers trying to do away with this category altogether. Its symptomatology was similarly far more diverse and inconsistent in the first half of the nineteenth century, often overlapping with other conditions such as monomania and moral insanity. Thus, while the term melancholia had been used to denote a form of illness or madness in medical literature since antiquity, the biomedical model of melancholia that emerged in the mid-nineteenth century was historically new and conceptually different from any earlier meanings of the term.

Two developments in particular were foundational to this new model of melancholia. The first was the uptake of physiological language and concepts into psychological medicine. In the early decades of the nineteenth century, physicians began to appropriate language from experimental physiology to speak about the perceived internal operations of ideas and emotions. Such models became central to the development of modern psychiatric concepts, particularly that of disordered mood. The emergence of what became known as physiological psychology and its significance for mid-to-late nineteenth-century conceptions of mind have been considered in detail elsewhere. ${ }^{15}$ The role of physiological models of mental pathology in the creation of modern mood disorders is, however, largely absent from the history of psychiatry. The reconfiguration of melancholia as a biomedical disease and a form of affective insanity was dependent upon the creation of 'disordered emotion' as a medical category. It follows that in order to adequately map the evolution of nineteenth-century melancholia one must trace how the idea of disordered and pathological emotionality was constituted and appropriated by medical psychologists to speak about mental disease.

The second key development was the institutionalisation of medical statistics together with a standardisation of recording practices in asylums across Britain. Following the creation of the Lunacy Commission in 1845 , diagnostic practices were increasingly carried out within an administrative framework heavily reliant upon asylum statistics. While historians of psychiatry have made considerable use of asylum statistics in constructing various narratives, both local and on a wider geographical scale, the relationship between such numerical data and the creation of an increasing number of diagnostic categories in nineteenth-century psychological medicine has been curiously neglected. As I demonstrate 
in Chapters 5 and 6 of this book, statistical and recording practices were crucial in shaping melancholia as a modern diagnostic category. In sum, nineteenth-century melancholia was constituted through the interplay between the language of physiological psychology, statistical practices, and clinical diagnostics, which together facilitated the creation of a modern biomedical disease concept.

Central to the developments described above was the use of metaphorical language to explain mental operations. ${ }^{16}$ As a form of affective insanity, melancholia was a disease perceived to rarely leave internal marks on patients' brain tissue. Through the application of metaphors borrowed from experimental physiology, such as 'irritation', 'reflex', and 'tone', disordered emotion could be explained as a defective physiological process. Moreover, the biomedical language of physiology contributed to a conceptual and linguistic shift in the description of external 'symptoms' of melancholia. Symptoms such as 'depression' and 'mental pain' (or 'psychalgia') rose to prominence in the second half of the nineteenth century. These terms have a history that pre-dates modern scientific medicine. Within the framework of a physiologically constituted model of mental pathology, older terms were imbued with new meanings. The language used by medical writers to explain mental phenomena is central to the present story, and the semantic ambivalence of medico-psychological terminology will gradually unfold in the subsequent chapters.

\section{A Note on Language}

While much of the medical and scientific terminology of the nineteenth century sounds familiar to the twenty-first reader, familiarity does not equate to sameness. This book attempts to strike a balance between contextual and historical sensitivity on the one hand, and rendering Victorian concepts intelligible in twenty-first-century language on the other. With that in mind, two words in particular that feature throughout this book warrant clarification.

1. Biomedical. Geneticists Craig Venter and Daniel Cohen have referred to the twenty-first century as 'the century of biology'. ${ }^{17}$ This pronouncement is perhaps a little premature, but what is more certain is that, over the last century and a half, biology has become central to how we understand ourselves and the world around us. In its modern meaning, that is, the way it gradually came to be used from the nineteenth century onward, biology is, broadly speaking, 'the science of life'. ${ }^{18}$ The scientists 
and doctors whose work is discussed in this book were concerned with the study of living organisms, a category that included human beings. It follows that many of the medical events and phenomena described in this book are referred to as biological. The organism-environment dualism emerged in this period and emotion was believed to be produced in the brain through the interaction-and disequilibrium-between the two. To describe melancholia in the mid-to-late nineteenth century as biological would, however, suggest only part of the picture. The condition was facilitated by the fusion of the new experimental sciences with medical knowledge, and is consequently referred to here as biomedical.

Biomedicine and its adjective did not come into use in the English language until the $1920 \mathrm{~s},{ }^{19}$ in other words, some two decades after the conclusion of the present story. Why, then, use it to describe nineteenth-century melancholia in a narrative that explicitly emphasises the importance of historical context and specificity? Following Clarke et al., I use 'biomedical' to denote 'the increasingly biological scientific aspects of the practices of clinical medicine' ${ }^{20}$ While the term biomedical belongs to the twentieth and twenty-first centuries, the process it refers to began in the nineteenth. In the mid-to-late nineteenth century, melancholia was reconstituted along biological (primarily physiological) lines, and it was conceptualised as a disorder of emotion, bringing the latter within the purview of medical science in new ways. As will be seen in the story that unfolds, Victorian physicians became increasingly concerned with non-delusional affective insanity as well as with emotional disturbances not considered strictly pathological. This constituted a profound shift (or shifts) in perceptions of human life, of medicine, and of the health/illness dichotomy. When I began to research this book, I needed an adjective for this new melancholia that emerged, one that would encompass these developments and denote the distinctly modern quality of this disease concept. Moreover, while this book is concerned with historical specificity and change, it is just as much about continuity. Specifically, the continuity of a macro-ontology of emotion as a biological operation (physiological and automated) subject to medical interrogation. This definition of emotion was created through the appropriation of data from experimental physiology, an area of research that utilised new technologies and techniques to study the animal body. Situated within this framework, melancholia was construed in modern, scientific terms radically different from pre-nineteenth-century descriptions of melancholy madness. It became, in short, a new disease. Referring to this melancholia 
as 'biomedical' is intended to highlight this significant conceptual shift, in language familiar to the twenty-first-century reader.

2. Depression. Scholars writing histories of melancholia or melancholy have often done so under the assumption that underlying cultural and temporal differences in language and understanding is a more or less timeless condition, a mood disorder that corresponds largely to what is today known as clinical depression. At the same time, as suggested above, critics of the twenty-first-century model of depression that appears to grow increasingly inclusive and opaque, have turned to past descriptions of melancholia in an attempt to show that there exists a core conditiona severe form of depression usually accompanied by psychosis-that has remained relatively stable across time, but which is becoming eclipsed by the current fashion of extending the term depression to an increasingly wide range of emotional states. These different but overlapping perceptions of melancholia and depression make it difficult to write a history of the former without also taking the latter into consideration. However, while it is important to acknowledge that a close link exists between nineteenth-century melancholia and the depressions of the twentieth and twenty-first centuries, the nature of this relationship should not be taken for granted. There is no inevitable and uncontested historical trajectory that leads from one to the other-such a linear development has been read and written into the histories of melancholia and depression by the people writing such histories.

'Depression' has been used unproblematically to speak about mental suffering in the eighteenth and nineteenth centuries. ${ }^{21}$ This is not simply a question of historians projecting modern terminology onto a past where it did not exist. The use of the term depression to denote a low mental state, such as profound sadness, has featured in the English language at least since the mid-seventeenth century. In this way, it was a metaphorical description of a mind or soul 'pressed down'; close in meaning to its literal, geometrical sense. ${ }^{22}$ In Victorian psychological medicine, 'depression' was reconstituted within the repertoire of words with strong physiological connotations, such as 'irritation', 'cerebral reflex', and 'tone'. In this context, it was equally used to denote low mood, but in a more literal (physical) sense than today, since the physiological framework allowed for a perception of mental functioning as lowered or slowed down. This phenomenon was often linked to decreased blood flow to the brain, and consequently impaired cerebral nutrition. Due to the multifaceted history of the term, it is difficult to pin down the medical roots of depression 
as a psychiatric symptom; however, its nineteenth-century meaning may have been at least partially appropriated from cardiovascular medicine. ${ }^{23}$ Depression used in this way became a key symptom of melancholia alongside 'mental pain' and 'suicidal tendencies'. It was also used as an umbrella category for various states of affective insanity characterised by low mood, often referred to as the 'states of mental depression', contrasted with the 'states of mental weakness' and the 'states of mental exaltation'. However, it is important to note that Victorian physicians did not speak of depression as a mental disease or disorder. Prior to the twentieth century, depression was a symptom or a unifying descriptive term, but it was not understood as a specific medical condition. Nineteenth-century usage of the word was more semantically different from ours than is generally acknowledged today. The tendency to equate nineteenth-century melancholia with today's depression can at least in part be attributed to a lack of contextual and semantic sensitivity displayed by scholars when using the term depression in pre-twentieth-century narratives. ${ }^{24}$

\section{Melancholy and Melancholia Before the Nineteenth Century}

While depression is, then, a strictly modern illness category, melancholia has a long history as a medical condition (or, rather, conditions), going back as far as the origins of the word, which derives from the Greek $\mu \dot{\varepsilon} \lambda \alpha \varsigma$

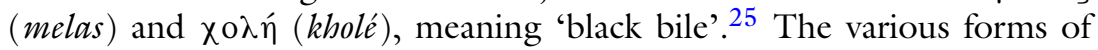
ancient, medieval, and early modern melancholias should not be grouped into one uniform, pre-modern category; nevertheless, Angus Gowland notes that ' $\mathrm{i}$ ] n terms of medical theory, the history of melancholy from antiquity to early modernity is predominantly one of continuity rather than change'. ${ }^{26}$ Taken together, these classical forms of melancholy or melancholia stand in stark contrast to the melancholia of the mid-to-late nineteenth century. Earlier versions, taken as a group, had strong links to the gastric region (as a result of the humoural hypothesis on which the disease concept was based), and were generally characterised by vivid delusions and a profound and debilitating sadness. ${ }^{27}$ While contemporary historians have referred to classical forms of melancholia as a 'mental disorder', ${ }^{28}$ it was not universally understood as a form of madness; medical and theological explanations often conflicted over its nature. Melancholy could be a temperament, a persona, a religious sentiment, or a sorrowful state of mind (or soul). Melancholia as a disease was, like other 
forms of illness, a humoural imbalance, believed to result from an excess of black bile. When the bile overflowed and rose to the head, clouding the mind and soul, this would produce sadness, fear, and delusions. In this regard it was often, but not always, perceived as 'a species of madness (delirium) involving the impairment of a principal internal mental faculty, and usually accompanied by groundless fear and sorrow' ${ }^{29}$

Despite numerous palpable similarities across centuries, the many premodern melancholias equally took on various distinct features specific to the cultural and temporal context of each form. Among early medieval monks, for instance, a prominent feature of melancholy and melancholia was acedia, 'a condition that particularly affected hermit monks in the desert'. ${ }^{30}$ Acedia was a negative, indifferent state of mind, in which one had little interest in or concern for one's surroundings. Described in fourth-century literature as a hatred of the present moment and a profound desire to be somewhere else, it was caused by the demon of acedia, also known as the 'middle of the day demon' from its tendency to appear during the hottest hours of the day among the monks who lived in desert colonies outside Alexandria. ${ }^{31}$ During the Baroque period, conversely, melancholy chiefly affected men of great artistry and intellectual abilities, and could result in terrifying delusions, such as the 'glass man' (believing oneself to be made of glass and thus fearful of being shattered into thousands of pieces). Other such early modern experiences of melancholy included the self-perception of being part man and part wolf, wild and uncontrollable (the 'wolf man'-a delusion given meaning and reality through popular stories about werewolves), as well as the sensation of being made entirely out of butter (thus prone to melt in the sun), or from straw (thus unable to stand up). ${ }^{32}$ In eighteenth-century England, melancholy became 'the English malady', an affliction primarily affecting persons of the upper classes whose 'nerves' were weak, and which was often linked to the cold, damp climate of the British Isles, as well as to the sedentary lifestyle of the landed gentry. ${ }^{33}$ This nervous affliction, overlapping with the 'vapours' and 'spleen', should be distinguished from the late nineteenth-century affliction 'nervous exhaustion' (or 'neurasthenia'), a condition brought on by a combination of the ills of modern urban life and too much 'brain work'. ${ }^{34}$ 


\section{The Changing Face of Melancholia}

As these historical vignettes indicate, melancholia is not, and never has been, one thing. The meaning of the word has changed over time, sometimes significantly, and other words have equally been used to describe emotional states that we might today associate with melancholia. For over two thousand years, doctors, philosophers, scientists, theologians, historians, artists, and writers have tried to make sense of low mood, in particular the shifting and often opaque boundary between health and illness. Anyone attempting to write a history of melancholia, whether as a form of madness, an emotion, a temperament, an artistic trope, or as depression previously called by a different name will, intentionally or not, add their story to a vast catalogue of scholarship spanning all of these perspectives, sometimes brought together in a single narrative. ${ }^{35}$ As the existing body of work on the history of melancholia attests, scholars continue to be drawn to the topic, attempting to understand where contemporary experiences of low mood fit in the wider context of human history. Our ability to experience profound and at times debilitating emotional depression appears to be a feature that unites the human species across temporal and cultural boundaries. At the same time, the range of experiences associated with melancholy, melancholia, and depression suggest that these psychological states come in an endless number of different shades and nuances.

To capture in a single narrative the multitude of imagery that is conjured up by the melancholia term is no easy feat, and it is harder yet to create order among this chaos of emotionality. One writer who has managed this with considerable skill and success is intellectual historian Karin Johannisson, whose history of melancholy is an apt illustration of its multifaceted nature. She maps some of the different ways in which low mood has been conceptualised and experienced in different societies in the West, showing how emotional expressions associated with melancholy have changed over time. In doing so she asks whether 'each epoch generates its own emotional repertoire'. ${ }^{36}$ While Johannisson suggests that hers is a history of the emotions rather than of medicine, she nonetheless draws heavily on medical sources in order to contextualise the 'experience' of melancholy, testifying to the difficulty in making any definitive distinction between medical condition and emotion. Her history of melancholy is, then, also a history of melancholia and of depression, which attempts to organise and differentiate types of melancholic qualities associated 
with different historical periods. Johannisson does this by separating low mood into three, temporally anchored, shades of melancholy: black (early modern), grey (modern), and white (late modern). All three are presented in fragments, medical and popular notions intermingled and boundaries obscured. This mosaic presentation of what is at one moment a feeling and at the next a medical condition is poignant and aptly illustrative of how meanings attached to the terms melancholy, melancholia, and depression have not only changed over time, but how different and even conflicting notions of these concepts have often coexisted.

Broadly speaking, existing histories of melancholia can be divided into two camps: one emphasising continuity, the other historical specificity and change. ${ }^{37}$ Johannisson's study exemplifies the latter, while Stanley Jackson's comprehensive work on melancholia and depression through the ages takes a continuity perspective. Melancholia and Depression: From Hippocratic Times to Modern Times, first published in 1986, remains the most ambitious attempt to date to piece together a coherent history of low mood spanning more than two millennia. Jackson frames his narrative as the history of depressive illness, suggesting that this condition, traditionally known as melancholia, has shown 'both a remarkable consistency and a remarkable coherence in the basic cluster of symptoms' across time. ${ }^{38}$ More recently, Clark Lawlor has attempted a similarly expansive history that traces melancholia from ancient Greece to the twenty-first century. Lawlor laments the end of a centuries-old continuity with the 'paradigm-changing arrival' of the third edition of the American Psychiatric Association's Diagnostic and Statistical Manual of Mental Disorders (DSM-III) in 1980, which produced a new depression based solely on descriptive psychopathology and which expanded into the realm of normal sadness. ${ }^{39}$ Edward Shorter is similarly critical of the DSM approach to mood disorders. He argues for the existence of two distinct forms of depression, one that is endogenous (melancholia), and a socially and culturally produced category, what is today the main form of depressive illness diagnosed in primary care. ${ }^{40}$

Contrasting these narratives with a focus weighted towards historical change, Judith Misbach and Henderikus Stam have traced a conceptual shift in the nineteenth century whereby melancholia was 'gradually reconceptualized as depression' through a process of 'medicalization'. 41 While their study is limited and places particular focus on the relationship between melancholia and neurasthenia, it forms an important contribution to the history of depressed mood. Their narrative follows 
on from German Berrios, who emphasises the role of French alienist Esquirol's idiosyncratic term lymemanie ('sadness mania') in the reconfiguration from intellectual to emotional insanity, arguing that, while the term was only ever used by French and Spanish physicians, it nonetheless helped bring about a change in meaning of the term melancholia, before the latter became gradually replaced by depression. For Berrios, there is little conceptual difference between late nineteenth-century melancholia and early twentieth-century depression. It is primarily a terminological change in large part driven by a preference for the latter term as it 'evoked a "physiological" explanation'. ${ }^{42}$ As these narratives imply, there was no straightforward transition from melancholia to depression-the former was not simply replaced by the latter. However, within existing histories tracing the reconfiguration of the melancholia concept in the nineteenth century, two events that were fundamental for this development have been almost completely overlooked. As I demonstrate in the chapters that follow, the shift in psychiatric knowledge relating to depressed mood was underpinned and driven by on the one hand the appropriation of language and concepts from experimental physiology to talk about emotion as a physiological event, and on the other by the role of asylum statistics in the development of diagnostic categories and criteria.

Existing histories of melancholia and depression such as those briefly outlined above testify to the historical instability of these medical concepts, which is foregrounded in Matthew Bell's cultural history of melancholia prior to the nineteenth century. Bell brings attention to the question of whether psychiatric disorders are natural kinds, which in turn speaks to problem of retrospective diagnosis. These issues are at the heart of debates about the relationship between pre-twentieth-century melancholia and today's depressive disorders. ${ }^{43}$ Since the nineteenth century, psychiatry's proponents and practitioners have not been averse to reading pre-modern accounts of various afflictions through the spectacles of modern medicine. For instance, Victorian physicians diagnosed Shakespeare's Hamlet with melancholia, ${ }^{44}$ twentieth-century psychiatrists have given World War I soldiers PTSD,${ }^{45}$ and medieval saints have been described as schizophrenic. ${ }^{46}$ Historians, too, have jumped on this bandwagon, to a lesser degree. ${ }^{47}$ The basic premise of this perspective is that categories of classification have changed, but the illnesses to which they refer have remained largely the same across time. 
The interlinked questions of retrospective diagnosis and natural kinds in psychiatry illustrate the perpetual tensions that characterise the historical study of illness, particularly of the psychiatric kind, between the universalist and the context-specific, and between the real and the constructed. Following Dominic Murphy, Bell rejects the 'false dichotomy' between 'mental disorders as natural kinds and mental disorders as socially constructed', arguing that psychiatric conditions 'with an organic component can very well have social causes too'. ${ }^{48}$ One might argue that there is also a more profound epistemological concern at the core of this debate, as the conceptual distinction between 'organic' and 'social' is historically specific to the modern period. Bracketing this question, however, I agree with Bell that there is no meaningful knowledge to be gained by asking whether or not melancholia is a real or constructed condition. All psychiatric conditions are constructed in the sense that the labels and the clusters of symptoms they refer to are not inevitable or discovered, they are the product of significant intellectual work (which in this book is taken to include a host of clinical and administrative practices and concerns, as well as the theoretical development of diagnostic categories). At the same time, psychiatric conditions are also very much real, insofar as people are diagnosed with them and experience themselves as suffering from such illnesses (this, I would argue, is what makes a psychiatric condition real, irrespective of any perceived organic cause). It follows that in the period with which this book is concerned, melancholia was very much a real condition. But while melancholia has existed as a medical term for over two millennia, the biomedical illness which that term came to denote in the nineteenth century was historically new. The aim of this book is to show how this condition was produced, that is, how melancholia was made into a modern biomedical mood disorder in the nineteenth century - how it was created, shaped, modified, and reified. In other words, it maps the events whereby this particular conception of melancholia was made real. ${ }^{49}$

\section{Melancholia And the History of Psychiatry}

Why study diagnostic practices? What is the value of such history? Michel Foucault remarked that diagnostic categories are not important in psychiatric medicine. The question is 'not whether it is this or that form of madness, but whether it is or it is not madness'. Everything else is little more than window dressing, an attempt by psychological 
medicine to resemble more closely its organic counterpart, indeed to be organic medicine, rather than to be like it. ${ }^{50}$ Psychiatric diagnoses are undoubtedly unstable, fluid, and contingent. But this is precisely why it is so important to subject them to scrutiny and critique. Diagnosis was paramount in nineteenth-century psychological medicine. Medical literature in the second half of the century devoted an extraordinary amount of attention to the difficult act of classifying various forms of mental disease. Each type of illness had to be distinguished from other forms as well as from non-pathological mental states. To be insane was not simply to be delusional.

Existing studies of madness and the asylum in the nineteenth century have contributed much to our understanding of institutionalisation and bureaucracy, and of the everyday practices of psychological medicine. Such histories have made intelligible the Victorian asylum, that odd, foreign place where a struggling profession attempted to treat a range of maladies that were poorly understood and for which there appeared to be few, if any, targeted cures. Much has been made of the struggle of a nascent psychiatric profession to assert itself, to prove its usefulness to society in general and the medical sciences in particular. ${ }^{51}$ There exists today a vast and rich catalogue of scholarship addressing the social and political history of psychiatry. Whether concerned with the ways in which power structures were reproduced and reinforced through psychiatric knowledge and institutions, ${ }^{52}$ or whether attempting to restore the patient as the protagonist of psychiatric history, ${ }^{53}$ social histories of madness and of the asylum have challenged traditional, clinically oriented and largely positivist narratives. ${ }^{54}$

The detailed and comprehensive records that British asylum staff were required to keep on their patients and institutions have provided historians with a wealth of rich source material on individual asylums as well as on the national lunacy bureaucracy. In-depth asylum studies have highlighted local practices and concerns in the context of a wider system in which asylums were increasingly subject to central directives and guidelines. Studies such as Joseph Melling and Bill Forsythe's compelling narrative of the Devon county asylums describe and interrogate the development of clinical knowledge and practices as well as the physical space of the asylum and life within its walls. ${ }^{55}$ Until recently, however, the ways in which these spaces and practices were productive of specific kinds of knowledge about mental disease have received limited attention, ${ }^{56}$ and the role played by asylum statistics in the creation and consolidation 
of psychiatric categories remains underresearched. ${ }^{57}$ Nevertheless, while diagnostics and classification have rarely been the central focus of existing asylum studies, ${ }^{58}$ they have featured as part of broader narratives. For instance, Melling and Forsythe note the high prevalence of melancholia in the Devon county asylums, as well as concerns among staff over the treatment of suicidal patients, who were placed on a 'special ward where attendants could be vigilant at night'. ${ }^{5}$

The picture in the South-West of England was mirrored elsewhere in the country. The number of people admitted to asylums in Britain and diagnosed with melancholia rose sharply in the second half of the nineteenth century, and the management of suicidal patients posed a growing challenge for asylum staff and lunacy commissioners alike. Several physicians noted that the number of melancholic patients increased at a higher rate than admissions overall, prompting discussions over whether more people were suffering from low mood than in the past, or whether such individuals were more likely than previously to be admitted into the asylum. Melancholic patients were rarely seen as posing a danger to others, but they were often believed to be a danger to themselves. The late nineteenth century saw a growing tendency to label melancholics as suicidal on medical certificates, but as discussed in Chapters 5 and 6, the meaning of 'suicidal' was ambiguous. Nevertheless, asylum physicians were increasingly concerned with the correct description and diagnosis of melancholia, and tried to the best of their abilities to identify, label, and categorise the multitude of expressions and behaviours met within their patients and which were seen as indicative of melancholic illness.

The history of melancholia in this period is, then, not just the history of psychiatric knowledge, but also of asylum practices, and of the range of human activity that was read by physicians as signs of melancholia. From the often hastily scribbled notes in asylum casebooks, the twentyfirst-century reader catches a glimpse of the human suffering that was translated into diagnostic terms such as 'depressed mood', 'suicidal tendencies', and 'religious delusions'. Snippet quotations tell of people haunted by oppressive feelings of guilt and shame, people who feared that their sins were so grave that they had forfeited the right to live, people who believed themselves persecuted by the devil, or who were convinced that the world was about to come to an end. In short, there is little question that the human beings to whom the melancholia label was affixed often experienced great pain and despair. 
It follows that 'experience' looms large over the history of melancholia, as it does over historical scholarship more broadly. A source of frustration for some historians and of fascination for others, experience is that slippery, perpetually unstable concept that can neither be pinned down nor ignored. The relationship between knowledge and experience is a particularly difficult, indeed often treacherous, space to navigate. When new knowledge and forms of classification are established, new facts are created. One way of understanding this process holds that psychiatric knowledge offers new ways of experiencing psychological phenomena, and that experience is subsequently fed back into the new categories, reinforcing these-producing what Ian Hacking has called a 'looping effect'. ${ }^{60}$ While the culturally and historically contingent nature of experience has been convincingly demonstrated, ${ }^{61}$ it remains a central, if contested, feature of the history of psychiatry, and the history of melancholia is no exception. The experiences of people diagnosed with melancholia lay beneath and informed the intellectual work that produced diagnostic language and, more broadly, psychiatric knowledge, but they are not the focus of this story. Not because they are not important, but because the object of scrutiny here is psychiatric knowledge: the aim is to understand how psychiatry creates its facts and truths. To the extent that patients feature in the present narrative, they do so primarily as descriptions and labels in textbooks, journal articles, asylum reports, and case notes.

This book takes classification to be a key event in the history of melancholia and depression, and of psychiatry more broadly. It has been a topic and source of much contention since the early years of the profession, and psychiatric categories have a significant, indeed sometimes life-changing, impact on the lives of individuals whose experiences are classified as mental disorders. To understand psychiatric knowledge, its role in care and treatment, and in shaping perceptions of selfhood, one must understand classification-how it is produced and applied, and the work it does in different contexts. Classification in psychiatry is primarily descriptive, and this has been the case since modern nosologies emerged in the nineteenth century. While physiology provided a useful framework for explaining disordered emotion, such models were of little practical use on asylum wards. They did not offer diagnostic tools to be deployed in determining the disease of a newly admitted patient. Instead, melancholia had to be identified and diagnosed according to a number of observable symptoms, primarily of the emotional kind. These could be deduced from 
communication with the patient, from enquiring into their actions prior to arriving in the asylum, and from observing the patient's demeanour, mode of speech, body language, motor function, and actions.

There was a dearth of home-grown British medical literature on insanity in the first half of the nineteenth century; no standard British nosology existed. Some physicians rejected melancholia as a diagnostic category, whereas others deployed it alongside other forms of chiefly emotional disorders, specifically monomania and moral insanity. However, in the second half of the nineteenth century melancholia was made increasingly coherent in British medical literature, in part though continuing uptake of German research. The disease picture that emerged was surprisingly consistent for a period when psychiatry was still an infant profession with few established norms and standards save for the legalities of incarceration and treatment. A physician who had read any of the major late nineteenth-century British textbooks on mental disease would know that the typical signs of melancholia were depressed mood, mental pain, despondency, despair, fear, delusions (often of a religious nature), refusal of food, inertia, restlessness, sleeplessness, and in some cases hallucinations, in particular hearing voices. Another key feature, which would become nearly as defining as the primary symptom of depressed mood, was the presence of suicidal tendencies. Melancholia was in many ways a broad medical concept, but it is misleading to dismiss the category, as one historian has done, as 'too vague and all-encompassing'. ${ }^{62}$ It was a broad concept, but towards the end of the century, the disease picture was seen as relatively coherent, stable, and homogenous. The illness was often divided into a number of subcategories, but key symptoms were largely seen to apply across the board. Descriptions of melancholia were anything but vague-they were detailed and precise, both in published literature and in asylum records.

Nineteenth-century classification of affective insanity holds a marginal place in existing scholarship on melancholia and depression, despite the continued influence of nosologies and methods of classification developed in this period. German Berrios notes that the taxonomy of insanity underwent a profound shift in the modern period, which included the introduction of 'time' as a diagnostic feature. Importantly, he also notes that the emergence of descriptive psychopathology arose out of 'the failure of the anatomo-clinical model of mental disease which left alienists with mere symptom descriptions' ${ }^{63} \mathrm{He}$ does not, however, address the other crucial development that emerged in response to the limits of 
anatomical models of mental disease: the appropriation of language and concepts from experimental physiology. As I show in subsequent chapters, these had a significant impact on how symptoms were interpreted, described, explained, and labelled. In this book, classification is understood as an historical event and a productive act. Melancholia was made (or re-made) in the nineteenth century as a modern, biomedical disease category. People who were diagnosed with melancholia were not incorrectly labelled; the act of diagnosing created melancholic patients, who in published material displayed a specific and largely consistent symptomatology. As will be seen in Chapter 6, however, the unity of this apparently coherent and delineated medical condition was achieved through the merging and flattening of a highly uneven and varied field of human experience through the use of standardised terminology and recording practices.

Before proceeding to tell this story, and bearing in mind the different concerns relating to melancholia and the history of psychiatry briefly outlined above, I want to emphasise what this book is not. It is not the history of an emotion. Neither is it a history of how people experienced melancholia in the nineteenth century. More broadly, it is not a social history of psychiatry or of the asylum as an institution. It is a history of a disease concept, specifically how this concept was reconfigured in nineteenth-century (primarily British) psychological medicine (later psychiatry). In this way, it is best understood as an intellectual history of psychiatric knowledge. ${ }^{64}$ Statements are here taken to be historical acts with a productive force, ${ }^{65}$ and clinical and administrative practices are taken to form part of the intellectual work that produced melancholia as a modern mood disorder. In mapping this process, the book draws on a range of sources, including psychiatric and medical textbooks, journal articles, legal records, lunacy commission directives, and asylum records, in particular statistical data and casebooks. In regard to the latter, Chapter 6 utilises records from several different asylums, each of which has its own particular history. Some of these institutions have been the focus of rich historical studies, which form part of an important and fascinating chapter in the history of madness and of medicine and society more widely. Here, however, asylum records are drawn upon for a specific purpose- to map how the melancholia diagnosis and its defining criteria were shaped and reified on the journey back and forth between case notes and published literature. Archival sources such as casebooks and 
diagnostic data sets are read as texts, part of a range of textual sources that together constitute what nineteenth-century psychiatrists said about melancholia and disordered mood at this time, and what knowledge was produced through these statements. To sum up, this book is the story of how melancholia was constituted as a specific type of illness in the nineteenth century: a modern mood disorder with a biomedical basis and a descriptive symptomatology.

\section{STRUCTURE OF THE BOOK}

The book begins in the early decades of the nineteenth century, when physiology was being established as the foundation of internal medicine. Chapter 2 maps the early appropriation of language and concepts from experimental physiology to explain mental phenomena. Through the works of early-to-mid-nineteenth-century physiologists and medical doctors schooled in the new science, the reader is introduced to the physiological origins of medico-psychological terms such as 'irritation', 'reflexion', and 'tone' that would be used to explain cerebral activity. These early writers provided the framework for the next generation of scientists who applied the findings of empirical research on sensory-motor action to the realm of ideas and emotion, and in doing so, established a new kind of mental science, physiological psychology. The chapter considers how Thomas Laycock and W.B. Carpenter, who had studied together in London, both created a model for mental reactivity, or psychological reflex action, that would form the framework for explaining disordered mood.

Chapter 3 picks up the historical trajectory of melancholia and affective insanity at a moment of significant change in perceptions of madness. Turn of the century asylum physicians and others treating the insane had increasingly favoured the new 'moral treatment', presented as a humanitarian and modern approach contrasted with older practices of restraint. This new approach not only transformed the treatment of the insane, but also ideas about what constituted insanity. The idea that one could be mad without being delusional was increasingly popularised in the first decades of the nineteenth century and provided an important philosophical foundation for the concept of disordered mood as a mental disease. The chapter traces the uptake of these ideas in mid-century British medical literature through the works of early influential physicians 
J.C. Prichard and John Conolly. Finally, the chapter notes how midcentury British asylum physicians began to draw on physiology to explain disordered mood, and how melancholia was gradually reconfigured within this context.

Chapter 4 maps the establishment of a new, scientific model of mental disease in British psychological medicine, through the uptake of physiology as well as German psychiatry into mid-Victorian medical literature. In Germany, psychiatry was an established academic discipline by the 1860s, and a new generation of doctors promoted a strictly biological approach to mental disease. The chapter traces the conceptual history of disordered mood from Wilhelm Griesinger's early work on psychological reflex action, through his later psychiatric publications, through to Richard Krafft-Ebing's 1874 monograph on melancholia, in which it is presented as a distinct psychiatric category with a clear neurobiological foundation. The chapter then goes on to consider how Henry Maudsley successfully merged physiology and mental pathology in one of the century's most influential textbooks on mental disease, in which established a firm division between 'affective' and 'ideational' insanity. The development of this new approach to disordered mood is followed into the 1870s and 80s, where it was rapidly embraced by British asylum physicians across the country. Finally, melancholia is contrasted with neurasthenia, another nineteenth-century condition that was particularly popular in North America.

In Chapter 5 the story departs from internal medicine and turns instead to the administrative framework that was being constructed in Britain from the 1840s onward, where the creation of a national Lunacy Commission to oversee asylums produced a new bureaucracy of madness that sought to standardise diagnostic systems across the country. Asylum physicians were increasingly under pressure from lunacy commissioners to record a wide range of information about their patients, including symptoms and diagnoses, and compile such data into statistical tables and reports. Such numerical data was central to the standardisation of melancholia as a relatively stable and coherent diagnostic category with suicidality as a defining feature. The chapter goes on to show how the melancholia diagnosis coalesced around four distinct symptoms which became defining of the disease category in the last quarter of the century: mental pain, depression, suicidal tendencies, and religious delusions. We will see that these four keywords have remarkably different histories and that their emergence as defining symptoms of melancholia was the result 
of significant intellectual work coupled with new administrative practices as well as attempts to develop psychiatry as a medical profession and academic discipline.

Chapter 6 traces the processes of classification and diagnostics to the asylum ward. The casebooks of Edinburgh Royal Asylum form the focal point of the chapter, and are contrasted with records from other asylums. The chapter follows melancholia as it was reified through the circular and mutually constitutive relationship between asylum records and published material. Yet this relationship was also one characterised by tension and ambiguity. As narrative accounts of patients' mental states gave way to singular keywords, the description of symptoms appeared to become more precise and homogenous. The act of merging a range of expressions into descriptive key words facilitated more efficient recording of symptoms and presentation of cases in professional publications. At the same time, however, this practice changed what was recorded, producing new information about people. This chapter sheds light on the significant intellectual labour required to turn the chaos of human emotionality into neat medical categories.

Finally, the Conclusion briefly sketches out some of the shifts that began to occur at the turn of the century, in particular Emil Kraepelin's nosological division of insanity into dementia praecox and manicdepressive insanity, and Adolf Meyer's introduction of 'depression' as an illness category rather than a symptom of melancholia. These acts had significant consequences for the continued usage of the melancholia diagnosis, which rapidly declined in the twentieth century. The Conclusion places nineteenth-century melancholia in the context of twentiethand twenty-first-century debates around mood disorders, descriptive psychopathology, and the ubiquity of clinical depression, asking how a critical historical approach to disordered mood can help us better understand - and critique - contemporary medical views on emotional distress. Finally, the Conclusion suggests some of the possible implications of attempts to revive biomedical melancholia as a diagnostic category in present psychiatry, and of attaching psychiatric labels to the emotional life of human beings. 


\section{Notes}

1. Michel Foucault, History of Madness (London: Routledge, 2006 [1961]), 273.

2. Thomas S. Clouston, Clinical Lectures on Mental Diseases (London: J \& A Churchill, 1883), 35.

3. David Healy, The Antidepressant Era (Cambridge, MA: Harvard University Press, 1997).

4. See for instance Allan V. Horwitz and Jerome C. Wakefield, The Loss of Sadness: How Psychiatry Transformed Normal Sorrow into Depressive Disorder (Oxford: Oxford University Press, 2007).

5. Brandon H. Hidaka, "Depression as a Disease of Modernity: Explanations for Increasing Prevalence," Journal of Affective Disorders 140 (2012): 211 .

6. For a longer discussion of this approach in the context of the history of melancholia and depression, see Åsa Jansson, "Melancholia and Depression," Oxford Research Encyclopedia of Psychology (April 30, 2020), retrieved May 20, 2020, from https://oxfordre.com/psycho $\operatorname{logy} /$ view/10.1093/acrefore/9780190236557.001.0001/acrefore-978 $0190236557-\mathrm{e}-623$.

7. The resurrection of melancholia was the subject of an interdisciplinary meeting in Copenhagen, the proceedings of which were subsequently published as a supplement issue of Acta Psychiatrica Scandinavica. Acta Psychiatrica Scandinavica, 115, Supplement 433 (2007). See also Michael A. Taylor and Max Fink, Melancholia: The Diagnosis, Pathophysiology, and Treatment of Depressive Illness (Cambridge: Cambridge University Press, 2006); Max Fink and Edward Shorter, Endocrine Psychiatry: Solving the Riddle of Melancholia (Oxford: Oxford University Press, 2010); Gordon Parker et al., "Issues for DSM-5: Whither Melancholia? The Case for Its Classification as a Distinct Mood Disorder," American Journal of Psychiatry 167, No. 7 (2010): 745-747.

8. Max Fink and Michael A. Taylor, "The Medical, Evidenced-Based Model for Psychiatric Syndromes: Return to a Classical Paradigm," Acta Psychiatrica Scandinavica 117 (2008): 82-83.

9. See esp. Stanley W. Jackson, Melancholia and Depression: From Hippocratic Times to Modern Times (New Haven and London: Yale University Press, 1986); Mikkel Borch-Jacobsen, Making Minds and Madness: From Hysteria to Depression (Cambridge: Cambridge University Press, 2009); Clark Lawlor, From Melancholia to Prozac: A History of Depression (Oxford: Oxford University Press, 2012). For a more nuanced approach, but which nonetheless comes down on the side of the continuity narrative, see Somogy Varga, "From Melancholia to Depression: Ideas on a Possible 
Continuity," Philosophy, Psychiatry, \& Psychology 20, No. 2 (2013): 141155. For a critique of continuity narrative, see Jennifer Radden, "Is This Dame Melancholy? Equating Today's Depression and Past Melancholia," Philosophy, Psychiatry, \& Psychology 10, No. 1 (2003): 37-52.

10. Max Fink and Michael A. Taylor, "Resurrecting Melancholia," Acta Psychiatrica Scandinavica 115, S. 433 (2007): 15.

11. L.S. Jacyna, "Somatic Theories of Mind and the Interests of Medicine in Britain, 1850-1879," Medical History 26 (1982): 237. Emphasis in original.

12. William F. Bynum, "The Nervous Patient in Eighteenth- and NineteenthCentury Britain: The Psychiatric Origins of British Neurology," in The Anatomy of Madness: Essays in the History of Psychiatry, Vol. I: People and Ideas, eds. William F. Bynum, Roy Porter, and Michael Shepherd (London: Routledge, 1985), 90.

13. For psychiatric autopsies in nineteenth-century British psychiatry, see e.g. Jonathan Andrews, "Death and the Dead-House in the Victorian Asylum: Necroscopy versus Mourning at the Royal Edinburgh Asylum, c. 1832-1901," History of Psychiatry 23 (2012): 6-26; Jennifer Wallis, Investigating the Body in the Victorian Asylum: Doctors, Patients, and Practices (London: Palgrave Macmillan, 2017).

14. Clouston, Clinical Lectures, 37.

15. Kurt Danziger, "Mid-Nineteenth-Century British Psycho-Physiology: A Neglected Chapter in the History of Psychology," and Lorraine J. Daston, "The Theory of Will versus the Science of Mind," both in The Problematic Science: Psychology in Nineteenth-Century Thought, eds. William R. Woodward and Mitchell G. Ash (New York: Praeger, 1982); L.S. Jacyna, "The Physiology of Mind, the Unity of Nature, and the Moral Order in Victorian Thought," British Journal for the History of Science 14 (1981): 109-132, and "Somatic Theories of Mind"; Roger Smith, "Physiological Psychology and the Philosophy of Nature in Mid-Nineteenth Century Britain" (PhD diss., University of Cambridge, 1971).

16. Emily Martin's now classic essay offers an astute and important discussion of what happens when metaphorical (and value-laden) language eventually becomes reified and-seemingly-neutralised: Emily Martin, "The Egg and the Sperm: How Science Has Constructed a Romance Based on Stereotypical Male-Female Roles," Signs 16, No. 3 (1991): 485-501.

17. Craig Venter and Daniel Cohen, "The Century of Biology," New Perspectives Quarterly 21, No. 4 (2004): 73-77. 
18. William Lawrence suggested this term in English following Gottfried Reinhold Treviranus' Biologie as the 'philosophy of living nature'. See William Lawrence, Lectures on Physiology, Zoology, and the Natural History of Man: Delivered at the Royal College of Surgeons (London: Benbow, 1822), 52. As Nikolas Rose suggests, however, the term is multivalent; 'there is no one biology in this "biological age".' Nikolas Rose, "The Human Sciences in a Biological Age," Theory, Culture \& Society 30, No. 3 (2013): 5 .

19. The OED traces 'biomedicine' and 'biomedical' to 1922 and 1921 respectively; the terms did not, however, gain widespread popularity until after WWII.

20. Adele E. Clarke, Janet K. Shim, Laura Mamo, Jennifer R. Fosket, and Jennifer R. Fishman, "Biomedicalization: Technoscientific Transformations of Health, Illness and U.S. Biomedicine," American Sociological Review 68 (2003): 162.

21. E.g. Janet Oppenheim, 'Shattered Nerves': Doctors, Patients, and Depression in Victorian England (Oxford: Oxford University Press, 1991); Anita Guerrini, Depression and Obesity in the Enlightenment: The Life and Times of George Cheyne (Norman: University of Oklahoma Press, 2000); Lawlor, From Melancholia to Prozac; Margaret Sorbie Thompson, "The Mad, the Bad, and the Sad: Psychiatric Care in the Royal Edinburgh Asylum (Morningside), 1813-1894" (PhD diss., Boston University, 1984).

22. E.g. George Cheyne, An Essay of Health and Long Life, 2nd ed. (London: George Strahan, 1725), 100; George Berkeley, "Three Dialogues between Hylas and Philonous," in The Works of George Berkeley, Vol. II: Philosophical Works, ed. Alexander Campbell (Oxford: Clarendon Press, 1901), 98; David Hume, Essays, Moral and Political (Edinburgh: R. Fleming \& A. Alison, 1741), 145.

23. German E. Berrios, "Melancholia and Depression during the Nineteenth Century: A Conceptual History," British Journal of Psychiatry 153 (1988): 298-304; Judith Misbach and Henderikus J. Stam, "Medicalizing Melancholia: Exploring Profiles of Psychiatric Professionalization," Journal of the History of the Behavioral Sciences 42, No. 1 (2006): 41-59.

24. For a critique of the cultural universality of modern depression from an anthropological perspective, see Sushrut Jadhav, "The Cultural Origins of Western Depression," International Journal of Social Psychiatry 42 (1996): 269-286.

25. John C. Bucknill and Daniel Hack Tuke, A Manual of Psychological Medicine, 4th ed. (London: J \& A Churchill, 1879), 215; Roy Porter, The Greatest Benefit to Mankind: A Medical History of Humanity (New York and London: W. W. Norton, 1997), 56-60. 
26. Angus Gowland, "The Problem of Early Modern Melancholy," Past and Present 191 (2006): 86. See also Matthew Bell, Melancholia: The Western Malady (Cambridge: Cambridge University Press, 2014); Jennifer Radden, "Introduction," in The Nature of Melancholy: From Aristotle to Kristeva, ed. Jennifer Radden (New York: Oxford University Press 2000); Erin Sullivan, Beyond Melancholy: Sadness and Selfhood in Renaissance Britain (Oxford: Oxford University Press, 2016); Wolf Lepenies, Melancholy and Society (Cambridge, MA: Harvard University Press, 1992).

27. With the gradual decline in popularity of the humoural model, other explanations for melancholia emerged. For instance, Thomas Willis suggested in the seventeenth century that 'we cannot here yield, to what some Physicians affirm, that Melancholy doth arise from a Melancholick humor', rather, 'it ought to be affirmed, that this distemper doth sometimes first begin from the Brain, and the Soul dwelling within it.' Thomas Willis, Two Discourses Concerning the Soul of Brutes (London: Thomas Dring, 1683), 192.

28. Jeremy Schmidt, "Melancholy and the Therapeutic Language of Moral Philosophy in Seventeenth-Century Thought," Journal of the History of Ideas 65, No. 4 (2004): 583; Jackson, Melancholia and Depression, 29; Roy Porter, "Mood Disorders: Social Section," in A History of Clinical Psychiatry, the Origin and History of Psychiatric Disorders, eds. German E. Berrios and Roy Porter (London: Athlone Press, 1995), 409. Berrios refers to earlier (pre-modern) forms of melancholia as 'a rag-bag of insanity states'. German E. Berrios, "Mood Disorders: Clinical Section," in A History of Clinical Psychiatry, 385. See also Berrios, "Melancholia and Depression," 298.

29. Gowland, "Early Modern Melancholy," 87-88.

30. Karin Johannisson, Melankoliska rum: om ångest, leda och sairbarbet $i$ förfluten tid och nutid (Stockholm: Bonniers, 2009), 76.

31. Reinhard Kuhn, The Demon of Noontide: Ennui in Western Literature (Princeton, NJ: Princeton University Press, 1976), 39-64.

32. Johannisson, Melankoliska rum, 42-43. See also e.g. Willis, Soul of Brutes, 188: "[S]ome have believed themselves to be Dogs or Wolves, and have imitated their ways and kind by barking or howling; others have thought themselves dead, desiring presently to be buried; others imagining that their bodies were made of glass, were afraid to be touched lest they should be broke to pieces.' Cf. 'mania lupina', in where 'sufferers [were] displaying strongly negative aspects of wolfish behaviour: they are wild, riotous and can only be placated with great difficulty using shackles.' Nadine Metzger, "Battling Demons with Medical Authority: Werewolves, Physicians, and Rationalization," History of Psychiatry 24, No. 3 (2013): 346. 
33. See e.g. George Cheyne, The English Malady, or, a Treatise of Nervous Diseases of All Kinds, as Spleen, Vapour, Lowness of Spirits, Hypochondriacal or Hysterical Distempers (London: George Strahan, 1733).

34. George Beard, A Practical Treatise on Nervous Exhaustion (Neurasthenia), Its Symptoms, Nature, Sequences, Treatment (New York: William Wood, 1880 ).

35. Notable works include: Bell, Melancholia; Angus Gowland, The Worlds of Renaissance Melancholy: Robert Burton in Context (Cambridge: Cambridge University Press, 2006); Johannisson, Melankoliska rum; Lawlor, From Melancholia to Prozac; Darian Leader, The New Black: Mourning, Melancholia and Depression (London: Hamish Hamilton, 2008); Lepenies, Melancholy and Society; Radden, The Nature of Melancholy; Sullivan, Beyond Melancholy.

36. Johannisson, Melankoliska rum, 13. This question has also been posed by Barbara Rosenwein, who uses the term 'emotional communities' to describe the different ways in which emotions have been experienced in different times and cultures. Barbara H. Rosenwein, "Worrying about Emotions in History," American Historical Review 107, No. 3 (2002): 821-845.

37. David Walker and Anita O'Connell give significant weight to both perspectives, suggesting that pre-modern descriptions of low mood 'certainly [appear] to match' DSM criteria for depression, but that 'because those specific frameworks, no longer exist ... earlier forms 'of melancholy cannot be said to be the same as depression.' David Walker and Anita O'Connell, "Introduction," in Depression and Melancholy, 1660-1800, Vol 1: General Introduction os Religious Writings, eds. Leigh Wetherall Dickson, Allan Ingram, David Walker, and Anita O'Connell (London: Pickering \& Chatto, 2012).

38. Jackson, Melancholia and Depression, ix.

39. The same argument has been made previously by Allan Horwitz and Jerome Wakefield in their critical analysis of the creation of Major Depressive Disorder. It is worth noting that Robert Spitzer, the head of the DSM-III task force who was a key target of Horwitz and Wakefield's critique, took on board some of their criticisms, and even wrote a preface to their book where he noted that 'Dr. Wakefield has critiqued my efforts in ways that I have largely become convinced are valid'. Robert Spitzer, "Preface," in Horwitz and Wakefield, The Loss of Sadness, viii.

40. Edward Shorter, "The Doctrine of the Two Depressions in Historical Perspective," Acta Psychiatrica Scandinavica 115, S433 (2007): 5-13. Falling somewhere between a continuity perspective and one that emphasises historical shifts, George Rousseau perceives the distinction between two forms of depression to be chiefly historical, in the form of 'a premedicalized category (melancholia) and a post-medicalized (depression).' 
Nevertheless, he holds that 'the older version contained a sufficient quantity of the characteristics of the newer to permit the conceptualization of a "history of depression" as if it had been a single, continuous category.' George Rousseau, "Depression's Forgotten Genealogy: Notes towards a History of Depression," History of Psychiatry 11 (2000): 74.

41. Misbach and Stam, "Medicalizing Melancholia," 44-45.

42. Berrios, "Melancholia and Depression," 300-301.

43. Bell, Melancholia, 3.

44. William F. Bynum and Michael Neve, "Hamlet on the Couch," in The Anatomy of Madness: Essays in the History of Psychiatry, Vol. I: People and Ideas, eds. William F. Bynum, Roy Porter, and Michael Shepherd (London: Routledge, 1985), 290.

45. See for instance Chapter 17 of Ian Hacking's Rewriting the Soul ('An indeterminacy in the past'), and the subsequent debate that played out on the pages of the History of the Human Sciences, which has become known as the 'Chapter 17 debate': Wes Sharrock and Ivan Leudar, "Indeterminacy in the Past?" History of the Human Sciences 15, No. 3 (2002): 95-115; Steve Fuller, "Making Up the Past: a Response to Sharrock and Leudar," History of the Human Sciences 15, No. 4 (2002): 115123; Ian Hacking, "Indeterminacy in the Past: On the Recent Discussion of Chapter 17 of Rewriting the Soul," History of the Human Sciences 16, No. 2 (2003): 117-124; Kevin McMillan, "Under a Redescription," History of the Human Sciences 16, No. 2 (2003): 129-150. See also Ian Hacking, Rewriting the Soul: Multiple Personality and the Sciences of Memory (Princeton, NJ: Princeton University Press, 1995).

46. Jerome Kroll and Bernard Bachrach, The Mystic Mind: The Psychology of Medieval Mystics and Ascetics (New York: Routledge, 2005), 25-28.

47. George Cheyne, for instance, an eighteenth-century physician who produced several comprehensive texts on the 'nervous disorders' of his time, and who also wrote publicly on his own struggles with these, has been described as suffering from 'depression' and 'obesity'. Guerrini, Depression and Obesity.

48. Bell, Melancholia, 8. See also Dominic Murphy, Psychiatry in the Scientific Image (Cambridge, MA: MIT Press, 2006).

49. My approach to the history of disease concepts and of the emotions is indebted to a number of writers, from history, sociology, anthropology, literature, and the philosophy of science. Of particular significance are: Georges Canguilhem, The Normal and the Pathological (New York: Zone Books, 1989); Thomas Dixon, From Passions to Emotions: The Creation of a Secular Psychological Category (Cambridge: Cambridge University Press, 2003); Michel Foucault, Psychiatric Power: Lectures at the Collège de France, 1973-74 (Basingstoke: Palgrave Macmillan, 2006), The Archaeology of Knowledge (London and New York: Routledge, 2002 [1969]), 
and History of Madness; Ian Hacking, "Making Up People," reprinted in Beyond the Body Proper: Reading the Anthropology of Material Life, eds. Margaret Lock and Judith Farquhar (Durham: Duke University Press, 2007), and "The Looping Effects of Human Kinds," in Causal Cognition: A Multidisciplinary Debate, eds. Dan Sperber, David Premack, and Ann James Premack (Oxford: Clarendon Press, 1995); Annemarie Mol, The Body Multiple: Ontology in Medical Practice (Durham: Duke University Press, 2002); Adrian Wilson, "On the History of Disease-Concepts: The Case of Pleurisy," History of Science 38, No. 3 (2000): 304-305; Allan Young, The Harmony of Illusions: Inventing Post-Traumatic Stress Disorder (Princeton, NJ: Princeton University Press, 1995).

50. Foucault, Psychiatric Power, 266.

51. E.g. Andrew Scull, The Most Solitary of Afflictions: Madness and Society in Britain 1700-1900 (New Haven: Yale University Press, 1993); Eric J. Engstrom, Clinical Psychiatry in Imperial Germany: A History of Psychiatric Practice (Ithaca, NY: Cornell University Press, 2004); Misbach and Stam, "Medicalizing Melancholia".

52. See for instance Foucault, Psychiatric Power and History of Madness; Marcel Gauchet and Gladys Swain, Madness and Democracy: The Modern Psychiatric Universe (Princeton, NJ: Princeton University Press, 1999); Andrew Scull, The Insanity of Place, the Place of Insanity: Essays on the History of Psychiatry (London: Routledge, 2006).

53. See for instance Ann Goldberg, Sex, Religion and the Making of Modern Madness: The Eberbach Asylum and German Society, 1815-1849 (Oxford: Oxford University Press, 1999); and on recovering the patient's perspective in the history of medicine more generally, see Roy Porter, "The Patient's View: Doing Medical History from Below," Theory and Society 14, No. 2 (1985): 175-198.

54. A good starting point for anyone wishing to explore the field is: Andrew Scull, ed., Madhouses, Mad-Doctors, and Madmen: The Social History of Psychiatry in the Victorian Era (Philadelphia: University of Pennsylvania Press, 1981).

55. Joseph Melling and Bill Forsythe, The Politics of Madness: The State, Insanity, and Society in England, 1845-1914 (London: Routledge, 2006).

56 . The central role of asylum practices in the production of psychiatric and medical knowledge has increasingly become the focus of historical interrogation in recent years. Of particular importance is Sarah Chaney's book on the history of self-harm, which draws on records from Bethlem, as well as Jennifer Wallis' study shedding light of the significance of the body in the production of psychiatric knowledge, which centres on the Wakefield asylum. Both authors skilfully map the intellectual work that took place in these institutions in the processes of diagnosis, treatment, and (in the case of Wallis) post-mortem examinations. Sarah Chaney, Psyche on the Skin: A 
History of Self-Harm (London: Reaktion Books, 2017), Chapter 2; Wallis, Investigating the Body in the Victorian Asylum.

57. The use of statistics has also played a significant role in the formation and diagnosis of non-psychological disease concepts. See e.g. Lloyd G. Stevenson, "Exemplary Disease: The Typhoid Pattern," Journal of the History of Medicine and Allied Sciences 37, No. 4 (1982): 159-181.

58. An important exception is Trevor Turner's study of the records of Ticehurst in Sussex (which are briefly drawn upon in Chapter 6). Trevor Turner, A Diagnostic Analysis of the Casebooks of Ticehurst House Asylum, 1845-1890 (Cambridge: Cambridge University Press, 1992).

59. Melling and Forsythe, The Politics of Madness, 189.

60. In a critical interrogation of Hacking's approach, Chris Millard importantly reminds us that the tools we use to critique the presumed universality of existing concepts are themselves products of specific historical contexts. In other words, we must be aware of 'the boundedness and historical specificity of the "malleable humanity"'. Chris Millard, "Concepts, Diagnosis and the History of Medicine: Historicising Ian Hacking and Munchausen Syndrome," Social History of Medicine 30, No. 3 (2017): 589.

61. Joan Wallach Scott, "The Evidence of Experience," Critical Inquiry 17, No. 4 (1991): 773-797.

62. Goldberg, Sex, Religion and the Making of Modern Madness, 5.

63. Berrios, The History of Mental Symptoms, 302.

64. My approach to the history of ideas is in particular indebted to Gadamer. See Hans-Georg Gadamer, Truth and Method (New York: Continuum, 2003 [1960]) and "The Problem of Historical Consciousness," in Interpretive Social Science: A Reader, eds. Paul Rabinow and William M. Sullivan (Berkeley: University of California Press, 1979).

65. I take my cue here from J.L. Austin and Judith Butler. J.L. Austin, How to Do Things with Words (Oxford: Clarendon Press, 1962), esp. pp. 68, 101-108, 120-122; Judith Butler, Excitable Speech: A Politics of the Performative (New York: Routledge, 1997). 
Open Access This chapter is licensed under the terms of the Creative Commons Attribution 4.0 International License (http://creativecommons.org/licenses/ by $/ 4.0 /$ ), which permits use, sharing, adaptation, distribution and reproduction in any medium or format, as long as you give appropriate credit to the original author(s) and the source, provide a link to the Creative Commons license and indicate if changes were made.

The images or other third party material in this chapter are included in the chapter's Creative Commons license, unless indicated otherwise in a credit line to the material. If material is not included in the chapter's Creative Commons license and your intended use is not permitted by statutory regulation or exceeds the permitted use, you will need to obtain permission directly from the copyright holder.

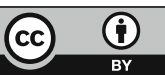

